\title{
Prevalence and Associated Factors of Diabetes Mellitus Among Adult Population in Hawassa Zuria Woreda, Sidama Region, Ethiopia
}

This article was published in the following Dove Press journal: Diabetes, Metabolic Syndrome and Obesity: Targets and Therapy

\author{
Yohannes Seifu (D) \\ Desalegn Tsegaw (iD ${ }^{2}$ \\ Yusuf Haji (iD ${ }^{2}$ \\ Amanuel Ejeso ${ }^{3}$ \\ 'Department of Biology, College of \\ Natural and Computational Science, \\ Hawassa University, Hawassa, Ethiopia; \\ ${ }^{2}$ School of Public Health, College of \\ Medicine and Health Sciences, Hawassa \\ University, Hawassa, Ethiopia; \\ ${ }^{3}$ Department of Environmental Health, \\ College of Medicine and Health Sciences, \\ Hawassa University, Hawassa, Ethiopia
}

Correspondence: Yohannes Seifu Department of Biology, College of Natural and Computational Science, Hawassa University, Hawassa, Ethiopia Email johnseifu80@gmail.com
Background: Diabetes mellitus (DM) is one of the main health problems in unindustrialized countries. According to the International Diabetes Federation report, adults living with diabetes were growing from time to time globally. Worldwide, diabetes mellitus accounts for $8.8 \%$ (424.9 million) morbidity and 4 million deaths. Ethiopia is one of the countries frequently affected by the disease with about 2.567 million $(5.2 \%)$ of its population affected with diabetes mellitus.

Objective: This study was aimed at determining the prevalence and associated factors of diabetes mellitus among adult population in Hawassa Zuria Woreda, Sidama Region, Ethiopia.

Methods: Community-based cross-sectional study was conducted from January 1 to February 15, 2019 among 519 adult population. A study participant was selected using a multistage sampling technique. We had employed the World Health Organization (WHO) stepwise method for non-communicable disease surveillance to collect the data. Fasting glucose meter was used from venous blood to test for blood glucose level. EPI info was used to enter and clean the data and the data were transported to SPSS for analysis. To assess associated factors with diabetes mellitus adjusted odds ratio (aORs) with 95\% confidence intervals (CIs) was employed and p.value $<0.05$ was considered significant.

Results: A total of 516 participants were included in the study. The diabetes mellitus prevalence was found to be $12.4 \%$ (95\% CI: 9.5-15.2). Factors associated with diabetes mellitus were being obese $[\mathrm{AOR}=9.2,95 \% \mathrm{CI}: 4.3,19.8]$, hypertensive (AOR=3.8, 95\% $\mathrm{CI}: 1.75,8.4)$, cigarette smoking ( $\mathrm{AOR}=7.8,95 \% \mathrm{CI}: 3.45,18.1)$ and high waist circumference (AOR=25, 95\% CI:8.5, 79).

Conclusion: This study revealed that the prevalence of diabetes mellitus was found to be high, which was greater than the estimated national prevalence of diabetes mellitus. Obesity, hypertension, cigarette smoking and high waist circumference were determinant factors for diabetes mellitus. Appropriate actions such as creating community awareness on regular blood sugar testing and preventive measures are recommended.

Keywords: prevalence, associated factors, diabetes mellitus, Hawassa Zuria Woreda

\section{Introduction}

Diabetes is a chronic disease that happens either while the pancreas does not produce adequate insulin or when the body cannot efficiently use the insulin it produces. ${ }^{1}$ Diabetes is one of the commonest non-communicable disease residues greatly prevalent with an aggregate incidence worldwide. Three major groups of DMs, namely, type $1 \mathrm{DM}$, type $2 \mathrm{DM}$, and gestational diabetes mellitus (GDM). ${ }^{1}$ 
Permitting to the International Diabetes Federation Atlas (IDFA) in 2017, estimation of more than 425 million people comprehensive have diabetes of which Africa accounts for about 16 million people with diabetes which is possible to rise by $156 \%$ in 2045 . $^{1}$

Diabetes mellitus is one of the main universal health emergencies of the twenty-first century. It is amongst the top 10 reasons for death occurred internationally and together with the other three significant noncommunicable diseases (NCDs) (cardiovascular disease, cancer, and respiratory disease) cause over $80 \%$ of all premature NCD death. ${ }^{1,2}$

Ethiopia is one of the nation's frequently affected by the disease. According to the 2017 report of IDF, the number of adults aged 20-79 years living with diabetes in the country was 2.567 million $(5.2 \%)$. And, the whole diabetes-related death was 30,972 accounts for $1 \%$ of the mortalities. ${ }^{2,3}$ According to WHO, Ethiopia had a profile, $3.8 \%$ (4.0\% amongst males and 3.6\% amongst females) of the population had diabetes morbidity in the year of $2016 .^{3}$

Preceding studies through the World stated the diabetes mellitus prevalence ranges from $1.4 \%$ to $13.55 \% .{ }^{14-32}$ Some of the factors associated with the incidence of diabetes encompassed: being overweight and obese, ${ }^{7,21-24,27,28,32}$ older age, ${ }^{17,18,21,31,32}$ having tertiary educational level, ${ }^{18,21}$ poor physical activity, ${ }^{31}$ having a family history of $\mathrm{DM},{ }^{21,22,29}$ low fruit and vegetable consumption, ${ }^{17}$ cigarette smoking, ${ }^{7,31}$ alcohol consumption ${ }^{15,22}$ waist to hip ratio (WHR), ${ }^{7,18,21,22,24,29}$ and being hypertensive. ${ }^{18,21,22,24,27-29}$

Accompanying continuing illustrative surveys to the extent is energetic to planning monitoring and evaluation of the effectiveness of health promotion and NCD preventive programs. However, there is a scarcity of research evidence recording magnitudes and risk factors of NCD in Ethiopia. ${ }^{4,5}$ Therefore, this study is aimed at determining the prevalence and associated factors of DM among adult population in semi-urban area, surrounding Hawassa City.

\section{Methods}

\section{Study Setting}

The study was conducted in Hawassa Zuria Woreda, Southern Ethiopia, with its capital town Dore Bafana, which is located $21 \mathrm{~km}$ southwest from Hawassa, the Regional Capital. The woreda is bordered at the North by Oromia regional state, at the East by Hawassa city administration, at the southeast by Boricha woreda, at the south by Balela woreda, and at the east by Oromia region. The Woreda is divided into 23 peasant administrations. Maize is the common crop produced in the woreda. The total population of the woreda, as projected from the 2007 national census, was 160,180 of which $81,692(51 \%)$ were females and 78,488 (49\%) were males. ${ }^{6}$

\section{Study Design, Period, and Sample Size}

A study was a community-based cross-sectional conducted from January, 1 to February 15, 2019. The source population of the study was all adult population above 18 years in Hawassa Zuria woreda who are living in the area for more than six months. And, the study population was adult population aged above 18 years living within eligible households in randomly selected Kebeles (smallest administrative unit) in Hawassa zuria Woreda. The sample size was calculated by a single population proportion formula bearing in mind a $6.5 \%$ prevalence of DM from the previous study, ${ }^{7} 3 \%$ desired precision, $95 \%$ confidence interval (CI), and a design effect of 2. Accordingly, the smallest sample size (n) intended was found to be 519 .

\section{Sampling Technique}

Multistage sampling technique was applied to select study participants. First, five kebeles (smallest administrative unit) were nominated randomly out of 23 kebeles in the district. Then, the sample was distributed to the nominated kebeles in proportion to the whole number of households in all kebele. Households in each kebele were selected through the systematic sampling technique via using the list of households as a sampling frame. $\mathrm{K}$ value for systematic sampling was 13 , and then every $\mathrm{k}$ household were selected. Lastly, one person was randomly selected from households with more than one eligible individual.

\section{Data Collection and Measurement}

A pretested structured interviewer-administered questionnaire was used to collect the data. And, physical measurements and biochemical measurement were modified from "WHO STEP" wise method for non-communicable diseases risk factor surveillance (STEPS). The questionnaire had three sections: socio-demographic and behavioral information, physical measurements (anthropometric and blood pressure), and biochemical tests. ${ }^{8}$

Step 1: Demographic and Behavioral Characteristic Data. In this stage, demographic and behavioral risk factors were collected via face-to-face interviews using an interviewer-administered questionnaire. 
Step 2: Blood pressure measurement: Blood pressure (BP) was taken in the sitting situation on the right arm by the mercury sphygmomanometer. Two evaluations were taken 5 minutes apart, and the average was considered as the final BP reading. Hypertension is demarcated as a systolic BP of $\geq 140 \mathrm{mmHg}$ or diastolic BP of $\geq 90 \mathrm{mmHg}$. Anthropometric measurements: Height was taken by a stadiometer, standing upright on a flat surface. Bodyweight was measured while wearing light clothes on an adjusted scale. Body mass index (BMI) was calculated by the formula: weight in kilograms divided by height in meters squared. A BMI $<18.5 \mathrm{~kg} / \mathrm{m} 2$ was considered underweight, $18.5-24.9 \mathrm{~kg} / \mathrm{m} 2$ was normal, $25-29.9 \mathrm{~kg} / \mathrm{m} 2$ overweight and $>30 \mathrm{~kg} / \mathrm{m} 2$ obesity. ${ }^{10}$ Waist circumference (WC) dignified at the estimated midpoint between the lower margin of the last palpable rib and the top of the iliac crest by elasticplastic tape. WC values $>94$ and $>80 \mathrm{~cm}$ for men and women respectively were measured high. ${ }^{11}$

Step 3: Biochemical measurements: using plain vacationer tubes $3 \mathrm{~mL}$ venous blood were got after an overnight fast $(\geq$ $8 \mathrm{hrs}$ ) at the communal. To allow clotting blood samples were left at room temperature for 15-20 minutes and centrifuged at $3000 \mathrm{rpm}$ for 10 minutes. Then sera were shifted into $2 \mathrm{~mL}$ Eppendorf tubes and stored at $+4^{\circ} \mathrm{C}$ for 1-2 hours at sampling sites and elated to Dore Bafano primary hospital. By using a chemistry analyzer (DIRUI CS 1248) the levels of glucose, total cholesterol (TC), and triglycerides (TG) were measured. The diagnosis of DM was based on the WHO 2006 with fasting blood glucose of over $\geq 126 \mathrm{mg} / \mathrm{dl}$ being diagnostic for DM. ${ }^{12}$ The optimum serum level for lipid profiles was careful as $<200 \mathrm{mg} / \mathrm{dl}$ for TC and $<150 \mathrm{mg} / \mathrm{dl}$ for TG in both genders as per the third report of the national cholesterol education program expert panel on detection, evaluation, and treatment of high blood cholesterol in adults. ${ }^{13}$

\section{Data Quality Control}

To safeguard the quality of the data, a pre-test was done on $5 \%$ of the questionnaire at neighboring Boricha district having similar socio-cultural characteristics with study subjects. Questionnaire was first prepared in English and translated into Sidamu Afo, a local language, and back translated into English by another translator to keep its consistency. The questionnaire was assessed for its clearness and the questions that were problematic to reply were restated. A four-day training on questionnaire administration, physical measurement, and biochemical measurement techniques were given to the data collectors five days earlier than the actual survey. Data were collected by five nurses, two health officers, and two-laboratory technicians. Earlier starting blood collection, laboratory technicians were invigorated on appropriate sample collection. To minimize observer error physical measurements were recorded twice and in some cases three times, whereas, rotation of data collectors was done to compare results. The glucometer device and strips were checked periodically for constancy in reference and test reading. The instrument DIRUI CS1248 chemistry analyzer was standardized by calibrator (Autocal) and quality control samples normal (Humatrol N) and pathological (Humatrol P) was run every day before running samples for tests. The entire processes of data collection were overseen by supervisors and the principal investigator. The collected info was regularly checked in the field by the supervisors.

\section{Data Management and Analysis}

Data were examined for completeness and consistency and any unfinished information was excluded from the entry. Coded data were entered and cleaned by EPI info version 3.5.1 stats package and transported to SPSS version 20 for analyses. Frequency distribution and percentage calculation were done to describe the socio-demographic characteristics and other variables. Adjusted odds ratio (AOR) with $95 \%$ confidence intervals (CIs) was calculated using logistic regression analysis. Variables with a p-value of less than 0.25 in bivariate analysis were candidates for multivariate analyses to control for potential confounders.

\section{Result}

\section{Socio-Demographic Characteristics}

Out of 519 selected adult participants, 516 were participated in this study giving a response rate of $99.4 \%$. Three persons were found inadequate for biochemical analysis and were excluded from the study. The median (interquartile range) age of the study participants was 35 (28-43) years. The Socio-demographic characteristics of the variables are shortened in Table 1.

\section{Behavioral Characteristics}

Around one-quarter of the participants had smoked cigarettes at least once in their lifetime of whom 100 (19.3\%) are current smokers. Among current smokers almost all, $98(98 \%)$ had smoked for less than four years. About 88 $(88 \%)$ of the smokers were categorized as a light smoker. Regarding alcohol consumption 124 (24\%) of respondents had drunk at least once in their lifetime while, $52(10.1 \%)$ 
Table I Socio-Demographic Characteristics of the Study Participants, Hawassa Zuria, 2019

\begin{tabular}{|c|c|c|}
\hline Variables & Frequency & Percentage \\
\hline \multicolumn{3}{|l|}{ Residence } \\
\hline Urban & 129 & 25 \\
\hline Rural & 387 & 75 \\
\hline \multicolumn{3}{|l|}{ Sex } \\
\hline Male & 323 & 62.6 \\
\hline Female & 193 & 37.4 \\
\hline \multicolumn{3}{|l|}{ Age } \\
\hline $18-24$ & 80 & 15.5 \\
\hline $25-34$ & 168 & 32.6 \\
\hline $35-44$ & 144 & 27.9 \\
\hline $45-54$ & 68 & 13.2 \\
\hline$\geq 55$ & 56 & 10.9 \\
\hline Median (IQR) age & $35(28-43)$ & - \\
\hline Educational Status & 60 & 11.6 \\
\hline Cannot read and write & 80 & 15.5 \\
\hline Read and write only & 140 & 27.1 \\
\hline Primary education & 112 & 21.7 \\
\hline Secondary education & 124 & 24 \\
\hline \multicolumn{3}{|l|}{ Diploma and above } \\
\hline \multicolumn{3}{|l|}{ Religion } \\
\hline Protestant & 444 & 86 \\
\hline Orthodox & 36 & 7 \\
\hline Catholic & 16 & 3.1 \\
\hline Muslim & 12 & 2.3 \\
\hline Others & 8 & 1.6 \\
\hline \multicolumn{3}{|l|}{ Occupation } \\
\hline Farmer & 244 & 47.3 \\
\hline Employee & 120 & 23.3 \\
\hline Daily laborer & 16 & 3.1 \\
\hline Merchant & 92 & 17.8 \\
\hline House wife & 44 & 8.5 \\
\hline \multicolumn{3}{|l|}{ Family size } \\
\hline I-3 persons & 144 & 27.9 \\
\hline 4-5 persons & 248 & 48.1 \\
\hline$>5$ persons & 124 & 24 \\
\hline
\end{tabular}

of them drink alcohol currently of which 48 (84.6\%) were categorized under light drinkers' (Table 2).

\section{Physical Measurements and Biochemical Tests of Participants}

From the total study participants, the prevalence of hypertension was 92 (17.8\%, 95\% CI: 14.5-21.1). Regarding waist circumference, 224 (43.3\%, 95\% CI: 39-47.7) of the participants had high waist circumference. Among study participants,
Table 2 Behavior and Feeding Characteristics Among Participants of Hawassa Zuria, 2019

\begin{tabular}{|c|c|c|}
\hline Variables & Frequency & Percentage \\
\hline \multicolumn{3}{|l|}{ Ever smoked Cigarettes $(n=5 \mid 6)$} \\
\hline Yes & $13 \mid$ & 25.4 \\
\hline No & 385 & 74.6 \\
\hline \multicolumn{3}{|l|}{ Smoke currently $(n=5 \mid 6)$} \\
\hline Yes & 100 & 19.3 \\
\hline No & 416 & 80.7 \\
\hline \multicolumn{3}{|l|}{ Smoking years $(n=100)$} \\
\hline$\leq 4$ & 98 & 98 \\
\hline$\geq 5$ & 2 & 2 \\
\hline \multicolumn{3}{|l|}{ Smoking dose $(n=100)$} \\
\hline Light smoker & 88 & 88 \\
\hline Moderate smoker & 3 & 3 \\
\hline Heavy smoker & 9 & 9 \\
\hline \multicolumn{3}{|l|}{ Ever consumed an alcohol } \\
\hline Yes & 124 & 24 \\
\hline No & 392 & 76 \\
\hline \multicolumn{3}{|l|}{ Current alcohol drink $(n=52)$} \\
\hline Yes & 52 & 10.1 \\
\hline No & 464 & 89.9 \\
\hline \multicolumn{3}{|l|}{ Alcohol dose $(n=52)$} \\
\hline Light & 48 & 84.6 \\
\hline Heavy & 4 & 15.4 \\
\hline \multicolumn{3}{|l|}{ Eat fruit in a week $(n=268)$} \\
\hline$<2$ days & 176 & 65.7 \\
\hline$\geq 3$ days & 92 & 34.7 \\
\hline \multicolumn{3}{|l|}{ Consumption of vegetable/wk } \\
\hline \multicolumn{3}{|l|}{$(n=234)$} \\
\hline I-2 days & 206 & 88 \\
\hline$\geq 3$ days & 28 & 22 \\
\hline \multicolumn{3}{|l|}{ Use of fatty food } \\
\hline Yes & 46 & 8.9 \\
\hline No & 470 & 91.1 \\
\hline \multicolumn{3}{|l|}{ Additional salt use } \\
\hline Yes & 45 & 8.7 \\
\hline No & 471 & 91.3 \\
\hline
\end{tabular}

50 (9.7\%, 95\% CI: 7.1-12.2) of them had $\geq 200 \mathrm{mg} / \mathrm{dl}$ of total cholesterol and $32(6.3 \%, 95 \%$ CI: $4.1-8.3)$ of the participants $\mathrm{had} \geq 150 \mathrm{mg} / \mathrm{dl}$ of triglyceride (Table 3 ).

\section{The Prevalence of Diabetes Mellitus}

The DM prevalence was found to be $64(12.4 \%, 95 \% \mathrm{CI}$ : 9.5-15.2). Of these, the proportion of previously undiagnosed DM was 48 (75\%) (Figure 1). 
Table 3 Physical and Biochemical Measurement of Participants in Hawassa Zuria, 2019

\begin{tabular}{|l|l|l|}
\hline Variables & Frequency & Percentage with 95\% Cls \\
\hline $\begin{array}{l}\text { Hypertension } \\
\text { Yes }\end{array}$ & 92 & $17.8(14.5-21.1)$ \\
No & 424 & 82.2 \\
\hline $\begin{array}{l}\text { Diabetes mellitus } \\
\text { Yes }\end{array}$ & 64 & $12.4(9.5-15.2)$ \\
No & 452 & 87.6 \\
\hline $\begin{array}{l}\text { Waist circumference } \\
\text { Normal }\end{array}$ & 292 & 56.6 \\
High & 224 & $43.4(39-47.7)$ \\
\hline Total cholesterol & & \\
$<200$ & 416 & 90.3 \\
$\geq 200$ & 50 & $9.7(7.1-12.2)$ \\
\hline Triglyceride & & \\
$<150$ & 484 & 93.8 \\
$\geq 150$ & 32 & $6.3(4.1-8.3)$ \\
\hline
\end{tabular}

\section{Factors Associated with Diabetes Mellitus}

In bivariate analysis variables like place of residence, age, sex, marital status, religion, occupation, family size, awareness about DM, khat chewing, coffee consumption, tea consumption, and recreational sport were not partially associated with DM (and P-value $>0.25$ ); However, marital status, educational status, alcohol consumption, fatty food feeding, additional salt use, means of transportation, body-mass-index cigarette smoking, hypertensive, high waist circumference, total-cholesterol levels, number of days eating fruit per week were found to be partially association with diabetes mellitus at p-value less than or equals to 0.25 and were candidates for multivariate analysis.

Accordingly, participants who were obese or overweight were 9.2 times more likely at risk of being DM positive than their counterparts ( $\mathrm{AOR}=9.2: 95 \% \mathrm{CI}: 4.3$, 19.8). Hypertensive respondents were at risk of developing DM that the odds of DM was about 4 times compared with those participants having normal blood pressure (AOR=3.8 95\% CI:1.75-8.4). The odd of developing DM among subjects with smoking habit was about 8 times linked to study participants who had never smoked in their lifetime (AOR=7.8, 95\% CI: 3.45, 18.1). Moreover, respondents who had high waist circumference were 25 times more likely to be DM positive compared to their counterparts (AOR=25, 95\% CI: 8.5, 79) (Table 4).

\section{Discussion}

To our best knowledge, this study was the first in Hawassa Zuria Woreda to assess the prevalence and associated factors of DM among the adult population. In this study, we have identified a high prevalence of diabetes mellitus in the study area. A huge percentage of the DM was undiagnosed and thus untreated. The associated factors to DM include obesity, being a smoker, being hypertensive, high waist circumference and high triglyceride levels.

This study revealed that DM prevalence is found to be $12.4 \%$. The results obtained are comparable to study done in East Gojjam, Ethiopia (11.5\%), in the Democratic Republic of Congo (11.7\%), in Eket, South Nigeria (13.7\%), and at Hawassa City, Ethiopia (12.2\%). ${ }^{14-16,31}$ Moreover, the result

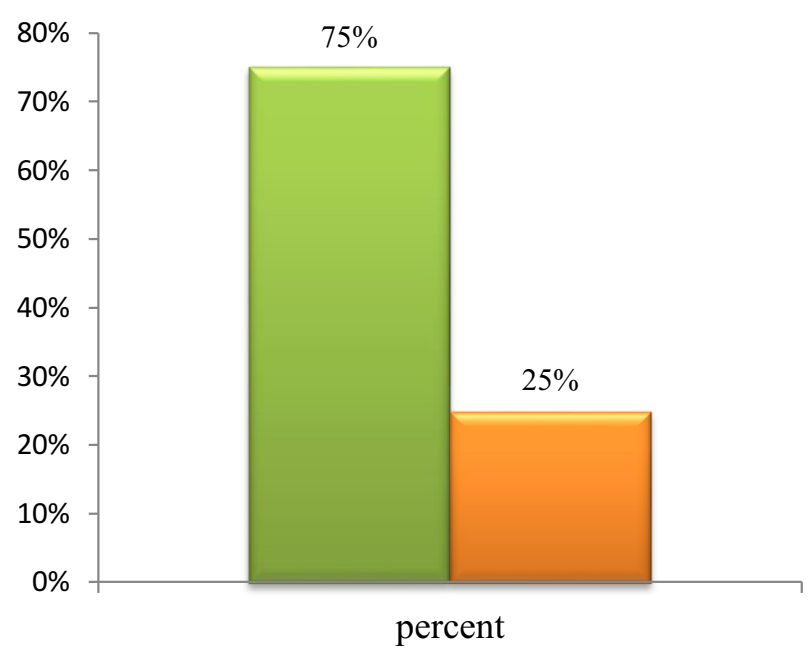

Figure I Distribution of previously diagnosed and undiagnosed DM among DM-positive participants. $\square$ Prevesiously undiadgnosed DM

$\square$ Prevesiously diadgnosed DM 
Table 4 Multivariable Analysis of Factors Associated with Diabetes Mellitus Among the Adult Population at Hawassa-Zuria Woreda, Southern Ethiopia, 2019

\begin{tabular}{|c|c|c|c|c|}
\hline \multirow[t]{2}{*}{ Variables } & \multicolumn{2}{|c|}{ Diabetes Mellitus Status } & \multirow[t]{2}{*}{ COR $95 \% \mathrm{Cl}$} & \multirow[t]{2}{*}{ AOR $95 \% \mathrm{Cl}$} \\
\hline & Yes & No & & \\
\hline \multicolumn{5}{|l|}{ Body mass index } \\
\hline Normal & 24 & 356 & I & 1 \\
\hline Over weight and Obese & 40 & 96 & $6.2(3.5,10.75)$ & $9.2(4.3,19.8)^{* *}$ \\
\hline \multicolumn{5}{|l|}{ Hypertensive } \\
\hline Yes & 36 & 64 & $4.7(2.69-8.25)$ & $3.8(1.75-8.4)^{* *}$ \\
\hline No & 28 & 388 & I & I \\
\hline \multicolumn{5}{|l|}{ Means of transportation } \\
\hline Foot & 40 & 324 & $1.5(0.9-2.6)$ & $0.47(0.2 .1 .13)$ \\
\hline Vehicle & 24 & 128 & I & I \\
\hline \multicolumn{5}{|l|}{ Smoking } \\
\hline Yes & 36 & 64 & $4.7(2.69-8.25)$ & $7.8(3.45-18.1)^{* *}$ \\
\hline No & 28 & 388 & I & \\
\hline \multicolumn{5}{|l|}{ Total cholesterol } \\
\hline$<200$ & 55 & $4 I I$ & I & I \\
\hline$\geq 200$ & 9 & 41 & $1.64(0.76-3.56)$ & $0.76(0.26-2.23)$ \\
\hline \multicolumn{5}{|l|}{ WHR } \\
\hline Normal & 8 & 284 & I & I \\
\hline High & 56 & 168 & II.8(5.5-25.4) & $25(8.5-79)^{* *}$ \\
\hline \multicolumn{5}{|c|}{ Fruit consumption days per week } \\
\hline $0-2$ & 48 & 376 & I & I \\
\hline$\geq 3$ & 16 & 76 & $1.65(0.89-3.1)$ & $1.02(0.37-2.9)$ \\
\hline
\end{tabular}

Note: **Indicated as p-value $\leq 0.01$.

is higher than other similar studies conducted in Ethiopia, namely in Mizan Aman (6.5\%), Dire Dawa city (8.95\%), Gilgel Gibe of Jimma zone (4.4\%), in Addis Abeba (5\%) and at Bishoftu town (5\%). 7,17,19-22 In the same way our result is much higher than prevalence of type 2 diabetes in other SubSaharan countries like $0.6 \%$ in rural Uganda, a study based on random plasma glucose test ${ }^{34}$ and $0.8 \%$ in rural Cameroon, a study based on fasting blood glucose test/oral glucose tolerance test. ${ }^{35}$ This variation may be due to variances in the period the studies were done, the area of the study, designs of the study, sample sizes used, the sociodemographic and life style of the studied population and the composition of the study population. For instance, the studies done in Bishoftu town, Gilgel Gibe and Dire Dawa City were encompassed both urban and rural areas and enormous sample sizes. While, the current study included somewhat smaller sample compared to the sample sizes of the other studies.

Amongst the issues with diabetes mellitus, the ratio of persons diagnosed to the undiagnosed was one to three
$(70 \%(n=48))$ of the study participants with diabetes were uninformed of their blood glucose level before the survey. If this survey was not conducted and if these participants were not included in the sample/survey, it means that these diabetic cases would seek health care after complications start to occur. That time would be too late to reverse diabetic-related complications. This revealed that is relatively higher than the reports from Southern Ethiopia ${ }^{18}$ and Addis Abeba. ${ }^{36}$ However, it is lower than undiagnosed diabetes in Mizan Aman $88.5 \%{ }^{7}$ and in North West Ethiopia $82.6 \%$ in rural setting. ${ }^{37}$ The high rate of undiagnosed diabetes may be due low cognizance of the people about the disease. This is probably owed to the low healthseeking behavior and subsequently, primary health-care facilities are not inclusive in developing countries unlike that in developed countries, ${ }^{3}$ another reason might be more attention given to communicable diseases and poor culture of medical checkup in developing countries. It is of critical importance to increase population awareness about chronic diseases like diabetes to enhance early diagnosis of the 
disease and management before its progression to life threatening complication.

In the current study, overweight and obese were found to be statistically significantly associated with having diabetes mellitus. This is consistent with other similar studies conducted in Mizan Aman, Kashmir India, Addis Abeba, Bishoftu, and Sidama zone. ${ }^{7,21-24}$ This influence is due to the condition that overweight and obese persons' adipose tissue discharges increased amounts of pro-inflammatory cytokines, non-esterified fatty acids, glycerol, hormones, and further factors that are intricate in the progress of insulin resistance. Insulin resistance is conveyed by the dysfunction of pancreatic islet $\beta$-cells the cells that release insulin to control blood glucose levels. Irregularities in $\beta$ cell purpose are therefore serious is crucial to the risk and development of DM. ${ }^{25}$

This study has shown that there was an important association between cigarette smoking and diabetes mellitus, which is consistent with other similar studies conducted elsewhere. $7,19,26$ There is an emerging body of evidence to show that smoking is a risk factor for diabetes mellitus. Cigarette smoking is certain of the known modifiable risk factor for diabetes mellitus both in industrialized and unindustrialized nations equally likewise confirmed by this study. ${ }^{3}$ Several hypotheses have been proposed to elucidate this link. The mechanism of smoking propagations the risk of diabetes and deteriorates glucose homeostasis has not been fully shown; nevertheless, the presented suggestion confirmations that the habit upsurges insulin resistance. Cigarette smoking has been recognized as a potential risk factor for insulin resistance, a forerunner for diabetes. Smoking has also been revealed to worsen glucose metabolism which may foremost to diabetes mellitus. ${ }^{2,3}$

Furthermore, waist circumference was one of the independent risk factors associated with diabetes mellitus in our study, which is also retained by other similar studies elsewhere. ${ }^{7,21,24}$ Furthermore, the proportion of individuals with high waist circumference $(32.6 \%)$ is remarkable in rural setting and may contribute to alarmingly increasing prevalence of diabetes, currently, in developing countries. Previous studies from Ethiopia indicated that high waist circumference is a risk factor for diabetes. ${ }^{7,18}$ Thus, our finding strengthens the idea that excess waist circumference plays a role in the development of type 2 Diabetes. Though not significant, participants with $\mathrm{BMI} \geq 25.0 \mathrm{~kg} / \mathrm{m} 2$ category have high chance of developing diabetes. Central obesity is one of the familiar modifiable risk factors associated with diabetes mellitus as per the WHO and IDF chronic noncommunicable disease surveys report in different countries. ${ }^{2,8}$ This is why abdominal fat accumulation clues to the secretion of highly active hormones called adipokines that maybe will damage glucose homeostasis.

Finally, the current study also revealed that the prevalence of hypertensive persons was found to be one-fifth of the participants and the odds of developing DM was about four times among hypertensive respondents. This outcome is in line with similar study results from Mizan Aman, South Africa, Bishoftu, and Sidama zone. ${ }^{7,22,24,28,29}$ This is higher than the prevalence reported in Koladiba, North West Ethiopia. ${ }^{28}$ This discrepancy might be due to older average age of this study population than that of Koladiba town.

This study was conducted in a large number of participants with proper sampling strategies which could enhance the representation of the study population. WHO's recommendation for fasting blood glucose and anthropometric measurements have been strictly followed. Standardized measuring tools were used. Involving adult populations from both urban and rural area could demonstrate the distribution of the problem to the general population. Our study was not free from limitations. For example, the study was not capable to categorize the different kinds of DM. Another limitation was diabetes mellitus was identified by glucose meter from capillary blood; which is not as reliable and accurate as plasma glucose estimation diagnosed by a spectrophotometer. Besides, the study was done among subjects with different lifestyle and work culture. Additionally, it is imaginable that participants did not trace their particular fasting time and this influence has pretentious the general prevalence of DM. Due to the cross-sectional nature of the study, we could not control temporal relationships between DM and the associated factors, for instance, triglycerides levels. Longitudinal research is needed to determine temporal and causal relationships between the covariates and DM. Another limitation of this study may be that other factors such as viral infection (like HIV) which may be associated with diabetes mellitus but were not recorded in this study. Activity and alcohol and substance consumption practices were only assessed by interview which may not be accurate due to recall bias.

\section{Conclusion}

This study revealed that DM prevalence in the study area was high when compared to national prevalence. 
Overweight and/or obese, hypertensive, smoking habit and high waist to hip ratio has higher odds of developing diabetes mellitus. Seventy-five percent (48 out of 64 ) of the diabetes cases were anew diagnosed in our study. We, therefore, recommend timely and proper screening and management of DM at the study area. And emphasis to be given to those population at risk of developing DM.

\section{Abbreviations}

AOR, adjusted odds ratio; BMI, body mass index; BP, blood pressure; CI, confidence interval, COR, crude odd ratio, DM, diabetes mellitus: FBS, fasting blood sugar; GDM, gestational diabetes mellitus, IDA, International Diabetes Federation; IRB, Institutional Review Board; NCD, noncommunicable diseases; RHB, Regional Health Bureau; SD, standard deviation; SHD, Sidama Zone Health Department, WHO, World Health Organization.

\section{Data Sharing Statement}

"The dataset will not be shared to protect the participants' identities".

\section{Ethical Consideration}

Ethical clearance and approval for this study was obtained from Institutional Review Board (IRB) of College of Medicine and Health Sciences, Hawassa University. Then a permission letter from the University was obtained and submitted to the Regional Health Bureau. And similar letter written by the Regional Health Bureau (RHB) was given to Sidama Zone Health Department (ZHD) and then to Hawassa Zuria Health Office (Dore Bafana). Additionally, a letter was given to all selected kebeles administration from the district. A written consent was obtained from all respondents after detailed clarification of the aim of the study. They had been given the right to refuse and assured of the confidentiality of the response. The privacy of the participants was kept through using unique code. All the methods were in line with the ethical clearance obtained. The outcomes of laboratory results were delivered to the study participants and those in need of medical attention were recommended to visit health institutions. Participants' informed consent included publication of anonymized responses, and that this study was conducted in accordance with the Declaration of Helsinki.

\section{Acknowledgments}

The authors wish to acknowledge Dore Bafano Primary Hospital and Tedagne Seifu for the financial provision of the study. We would like to extend our gratitude to Hawassa Zuria Woreda Health Office and to the community. We would also like to thank Mr Huriso (Seko) Seifu for his diligent language edition and moral support. The authors also recognize the invaluable funding certain by all who contributed in the study, particularly the study participants and data collectors.

\section{Author Contributions}

All authors made a significant contribution to the work reported, whether that is in the conception, study design, execution, acquisition of data, analysis and interpretation, or in all these areas; took part in drafting, revising or critically reviewing the article; gave final approval of the version to be published; have agreed on the journal to which the article has been submitted; and agree to be accountable for all aspects of the work.

\section{Disclosure}

We the authors state that we do not have any conflicts of interest.

\section{References}

1. WHO. World Health Organization Department of NonCommunicable Disease Surveillance. Geneva; 1999.

2. IDF DIABETES ATLAS international diabetes federation, 2017.

3. WHO. Global Report on Diabetes. Geneva: WHO; 2016.

4. Alemseged F, Haileamlak A, Tegegn A, et al. Risk factors for chronic non-communicable diseases at Gilgel Gibe Field Research Center, Southwest Ethiopia: a population-based study. Ethiop J Health Sci. 2012;22(special issue):2012.

5. FMOH. Health Sector Transformation Plan (HSTP): 2015-2019. Addis Ababa, Ethiopia: Federal Ministry of the health of Ethiopia (FMOH); 2015.

6. Office DBF. Dore Bafana Finance Office; 2018.

7. Aynalem SB, Zeleke AJ. Prevalence of diabetes mellitus and its risk factors among individuals aged 15 years and above in Mizan-Aman Town, Southwest Ethiopia, 2016: a cross-sectional study. Hindawi Int J Endocrinol. 2018;2018(931798):7.

8. WHO. The WHO STEP Wise Approach Surveillance of Risk Factors for Non-Communicable Diseases. Vol. 2017. Geneva: WHO; 2017.

9. AV C, GL B, HR B, Green WCC. The Seventh report of the joint national committee on prevention, detection, evaluation, and treatment of high blood pressure. 2003.

10. National Heart, Lung, Blood Institute, National Institute of Diabetes, Digestive, Kidney Diseases (US). Clinical Guidelines in the Identification Evaluation and Treatment of Overweight and Obesity in Adults; 1998.

11. WHO. Waist Circumference and Waist-Hip ratio.Report of a WHO Expert Consultation World Health Organization. Geneva: WHO; 2008.

12. WHO. Definition and Diagnosis of Diabetes Mellitus and Intermediate Hyperglycemia, Report of WHO and IDF Consultation 2012. Geneva: WHO; 2012.

13. National Institutes of Health Third Report of the National Cholesterol Education Program Expert Panel on Detection, Evaluation, and Treatment of High Blood Cholesterol in Adults (Adult Treatment Panel III), NIH Publication. 2011. 
14. Wondemagegn AT, Bizuayehu HM, Abie DD, Ayalneh GM, Tiruye TY, Tessema MT. Undiagnosed diabetes mellitus and related factors in East Gojjamb(NW Ethiopia) in 2016: a community-based stud. J Public Health Res. 2017;6:834. doi:10.4081/jphr.2017.834

15. Mawaw PM, Yav T, Mukuku O, et al. Prevalence of obesity, diabetes mellitus, hypertension, and associated risk factors in a mining workforce, Democratic Republic of Congo. Pan Afr Med j. 2017;28:282. doi:10.11604/pamj.2017.28.282.14361

16. Idem I, Ukoh G, Ekott E. Prevalence and risk factors of diabetes mellitus in Eket, South-South Nigeria. J Biotechnol Biochem. 2017;3:3.

17. Behailu Hawulte Ayele HS, Shunu A, Merid Mengesha M. Diagnosed and undiagnosed Diabetes mellitus among urban adults: a population-based cross-sectional stud. 2019. doi:10.1101/532705

18. Zekewos A, Loha E, Egeno T, Wubshet K, Merga Z. Prevalence of diabetes mellitus and associated factors in bona district, Sidama zone: a community based study. Ethiop J Health Sci. 2018;28(4):451. doi:10.4314/ejhs.v28i4.11

19. Seifu W, Tsehaineh B, Woldemichael K. Prevalence and risk factors for diabetes mellitus and impaired fasting glucose among adults aged 15-64 years in Gilgel Gibe Field Research Center, Southwest Ethiopia. MOJ Public Health. 2015;2:4.

20. Ethiopia. MOJ Public Health. 2015;2:4

21. Tesfaye T, Shikur B, Shimels T, Firdu N. Prevalence and factors associated with diabetes mellitus and impaired fasting glucose level among members of federal police commission residing in Addis Ababa, Ethiopia. BM Cendocine Disord. 2016;16:68. doi:10.1186/ s12902-016-0150-6

22. Megerssa YC, Gebre MW, Birru SK, Goshu AR, Tesfaye DY. Prevalence of undiagnosed diabetes mellitus and its risk factors in selected institutions at Bishoftu Town, East Shoa, Ethiopia. J Diabetes Metab. 2013;12.

23. Ahmad J, Masoodi MA, Ashraf M, et al. Prevalence of diabetes mellitus and its associated risk factors in age group of 20 years and above in Kashmir, India. AJMS. 2011;4(1):38-44.

24. Giday A, Wolde M, Yihdego D. Hypertension, obesity and central obesity in diabetics and non-diabetics in Southern Ethiopia. Ethiop $J$ Health Dev. 2010;24(2):145-147. doi:10.4314/ejhd.v24i2.62964

25. SE HR K, Utzschneider KM. Mechanisms linking obesity to insulin resistance and type 2 diabetes. nature. 2006;444:840. doi:10.1038/ nature 05482

26. Kapoor D, Bhardwaj AK, Kumars D, Raina SK. Prevalence of diabetes mellitus and its risk factors among permanently settled tribal individuals in tribal and urban areas in northern state of sub-himalayan region of India. Browse J. 2014.
27. Abebe SM, Getachew A, Fasika S, Bayisa M, Demisse AG, Mesfin N. Diabetes mellitus among HIV-infected individuals in follow-up care at University of Gondar Hospital, Northwest Ethiopia. BMJ Open. 2016;6.

28. Worede A, Alemu S, Gelaw YA, Abebe M. The prevalence of impaired fasting glucose and undiagnosed diabetes mellitus and associated risk factors among adults living in a rural Koladiba town, northwest Ethiopia. BMC Public Health. 2017;10:251.

29. AA Motala, Esterhuizen T, Gouws E, Pirie FJ, Omar MAK. Diabetes and other disorders of glycemia in a rural South African community. Diabetes Care. 2008;31.

30. Boden GSG. Free fatty acids in obesity and type 2 diabetes: defining their role in the development of insulin resistance and beta-cell dysfunction. Eur J Clin Invest. 2002;32:14-23. doi:10.1046/j.13652362.32.s3.3.x

31. Andargachew K, Endrias MW. Hypertension and diabetes mellitus among patients at Hawassa University comprehensive specialized Hospital, Hawassa, Southern Ethiopia. Int J Chronic Dis. 2019. doi: $10.1155 / 2019 / 2509242$

32. Kpozehouen A, Djrolo F, Sossa CJ, et al. Prevalence and associated factors of diabetes mellitus in Benin. Open $J$ Epidemiol. 2015;5:163-173. doi:10.4236/ojepi.2015.53021

33. Idem I, Ukoh G, Ekott E. Prevalence and risk factors of diabetes mellitus in Eket, SouthSouth Nigeria. IOSR J Biotechnol Biochem. 2017;03(03):32-35. doi:10.9790/264X-03033235

34. Maher D, Waswa L, Baisley K, Karabarinde A, Unwin N, Grosskurth H. Distribution of hyperglycaemia and related cardiovascular disease risk factors in low-income countries: a cross-sectional population-based survey in rural Uganda. Int J Epidemiol. 2010;40 (1):160-171. doi:10.1093/ije/dyq156

35. Mbanya JC, Cruickshank JK, Forrester T, et al. Standardized comparison of glucose intolerance in west African-origin populations of rural and urban Cameroon, Jamaica, and Caribbean migrants to Britain. Diabetes Care. 1999;22(3):434-440. doi:10.2337/diacare.22. 3.434

36. Nshisso LD, Reesea A, Gelaye B, Lemma S, Berhane Y, Williams MA. Prevalence of Hypertension and Diabetes among Ethiopian Adults. Diabetes Metab Syndr. 2012;6(1):36-41.

37. Abebe SM, Berhane Y, Worku A, Assefa A. Diabetes mellitus in North West Ethiopia: a community based study. BMC Public Health. 2014;14 (1):1-8. doi:10.1186/1471-2458-14-97

Diabetes, Metabolic Syndrome and Obesity: Targets and Therapy

Dovepress

\section{Publish your work in this journal}

Diabetes, Metabolic Syndrome and Obesity: Targets and Therapy is an international, peer-reviewed open-access journal committed to the rapid publication of the latest laboratory and clinical findings in the fields of diabetes, metabolic syndrome and obesity research. Original research, review, case reports, hypothesis formation, expert opinion and commentaries are all considered for publication. The manuscript management system is completely online and includes a very quick and fair peer-review system, which is all easy to use. Visit http://www.dovepress.com/testimonials.php to read real quotes from published authors. 